\title{
A sleeping giant?
}

\begin{abstract}
As the planet warms, vast stores of methane - a potent greenhouse gas — could be released from frozen deposits on land and under the ocean. Amanda Leigh Mascarelli reports on the race to understand a ticking time bomb.
\end{abstract}

n 2007, scientists scouting the icy waters of the Arctic Ocean began to notice some troubling signs. In about half of their seawater chemistry samples, the concentration of dissolved methane was two to ten times higher than in samples taken during previous years from the same locations. Then, last summer, they observed large rings of gas - sometimes as wide as 30 centimetres in diameter - trapped in ice, as well as methane plumes bubbling to the surface over hundreds of square kilometres of the shallow waters along the Siberian Shelf.

The team, from Russia and other nations, presented their results at the American Geophysical Union's Fall Meeting in December, where scientists cautiously voiced their concerns that large quantities of methane are becoming destabilized as the planet - and the

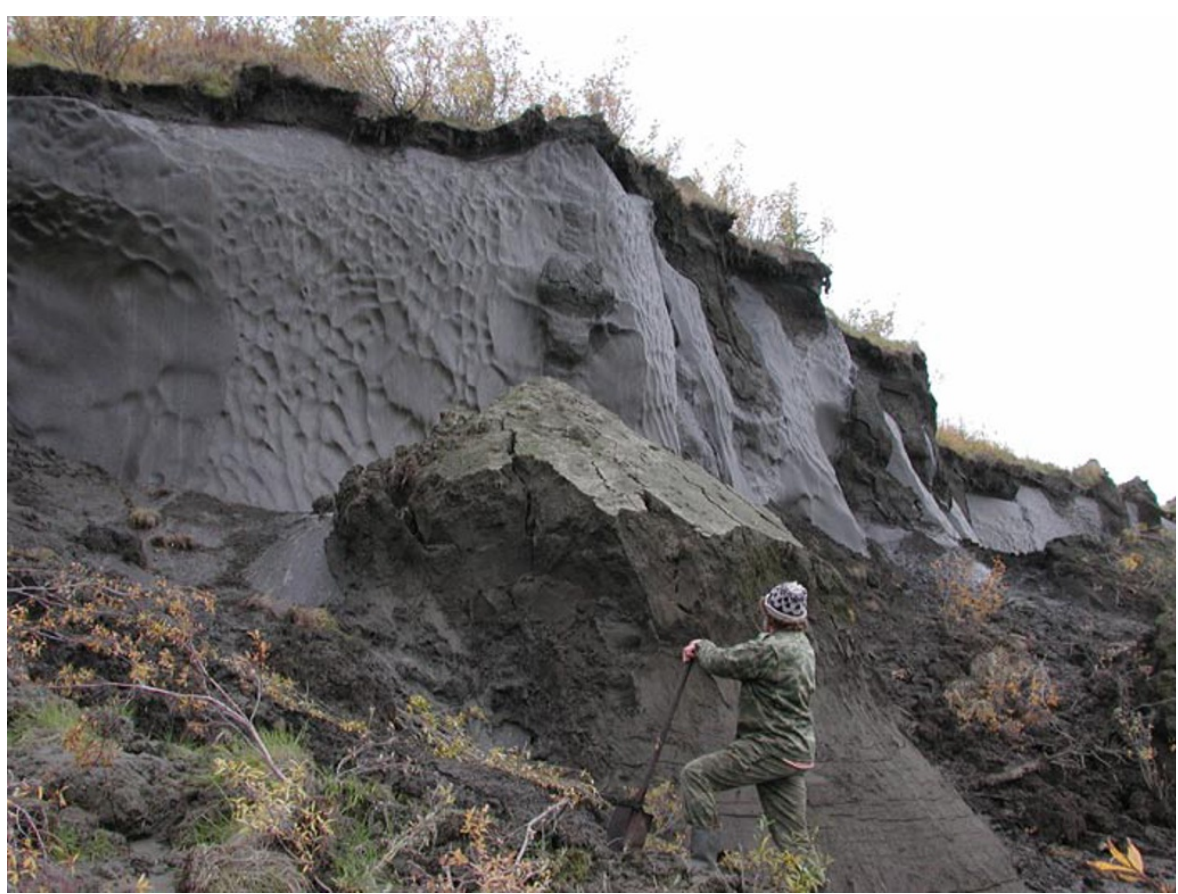

Arctic permafrost known as yedoma is beginning to release its rich store of ice-age organic carbon as the ground thaws. ocean - heat up. Researchers have long speculated that warming could unleash vast stores of the greenhouse gas from where it lies frozen beneath the sea floor and locked up in Arctic soils. If those deposits were to melt, it would almost certainly trigger abrupt climate change. Methane heats the atmosphere with an efficiency 25 times that of carbon dioxide, and its release could put in motion a positive feedback loop in which warming releases methane, causing further warming, which liberates even more of the gas. Whether that's already happening is anyone's guess. Scientists are quick to point out that the Arctic methane plumes could be anomalous or simply part of a longer-term trend. Natalia Shakhova, a biogeochemist at the University of Alaska, Fairbanks, and one of the leaders of the Siberian Shelf study, says, "Two years is nothing in geologic time scales." James Kennett, an Earth scientist at the
University of California, Santa Barbara, agrees and says it is very possible that the Arctic methane releases "just simply weren't observed before."

But the findings are part of a growing trend in which scientists are turning their attention to a threat conceivably worse than carbon dioxide. Though human activity has boosted atmospheric concentrations of methane by 150 per cent since the Industrial Revolution - mostly through agriculture and farming, the creation of landfills, biomass burning and fossil fuel use - that's nothing compared with the quantities that could be released from frozen deposits in the ground. "These deposits rival fossil fuels in terms of their size. It's like having a whole additional supply of coal, oil and natural gas out there that we can't control," says James White, a geochemist at the University of Colorado, Boulder.

Some of these deposits take the form of gas trapped within icy lattices of hydrogen bonds, known as hydrates or clathrates, that are tucked into pores of sediment below the sea floor. In shallow marine sediments such as those along the Siberian Shelf, hydrates are covered by a layer of frozen soil, called permafrost, that further protects them from melting. Both here and on land, permafrost stores vast quantities of carbon that could be converted to methane. Rich in organic material from dead plant and animal matter, thawed-out permafrost becomes alive with methaneproducing microbes, which release the gas to the atmosphere. Some have compared it to unplugging a giant freezer: warming temperatures could free up ancient carbon that's been safely tucked away for many thousands of years. "We've been putting carbon in this bank for 10,000 years," says White. "It's so cold that it doesn't decay away. But as the climate warms up, you start to take it out of the bank."

Although the rapid release of methane may sound like science fiction, it is not wholly far-fetched: methane has been suspected in nearly all of the dramatic warming spells in Earth's history. What's troubling to some is how little is currently 
known about the gas and its potential response to warming. "It's frightening that we can't even say what the background is," says Martin Kennedy, a geologist from the University of California, Riverside. "That's what's so alarming about the state of the field right now."

\section{LOOSENING THE LID}

The Siberian Shelf alone harbours an estimated 1,400 billion tonnes of methane in gas hydrates, about twice as much carbon as is contained in all the trees, grasses and flowers on the planet. If just one per cent of this escaped into the atmosphere within a few decades, it would be enough to cause abrupt climate change, says Shakhova. "When hydrates are destabilized, gas is released under very high pressure," she says. "So emissions could be massive and nongradual." Shakhova and her colleague Igor Semiletov of the University of Alaska, Fairbanks, believe the plumes they've observed confirm previous reports that the permafrost cap is beginning to destabilize, allowing methane to escape from the frozen hydrates below. "Subsea permafrost is like a rock," explains Semiletov. "It works like a lid to prevent escape of any gas. We believe that the subsea permafrost is failing to seal the ancient carbon pool." But Carolyn Ruppel, a geophysicist with the US Geological Survey in Woods Hole, Massachusetts, isn't yet ready to attribute the methane plumes to a breakdown in methane hydrates in the subsea permafrost. "We have proof from studies that have been carried out in the past few years that there's a lot of methane in certain shallow marine environments offshore in the Arctic," says Ruppel. "But can we prove that the methane comes from methane hydrates? That is a critical question."

Although methane hydrates are perhaps the biggest wild card in the system, scientists are equally, if not more, concerned about thawing permafrost in the Arctic, where changes are already underway. Permafrost in the Northern Hemisphere is thought to contain some 950 billion tonnes of carbon; a little less than half of that is stored in highly organic-rich permafrost known as yedoma, much of which has been frozen since the Pleistocene, 10,000 years ago. Yedoma occupies about one million square kilometres of land, mostly in Siberia, where Katey Walter, an ecologist from the University of Alaska, Fairbanks, navigates rivers and lakes, frozen soil and even protruding mammoth bones to study methane emanating from the thawing

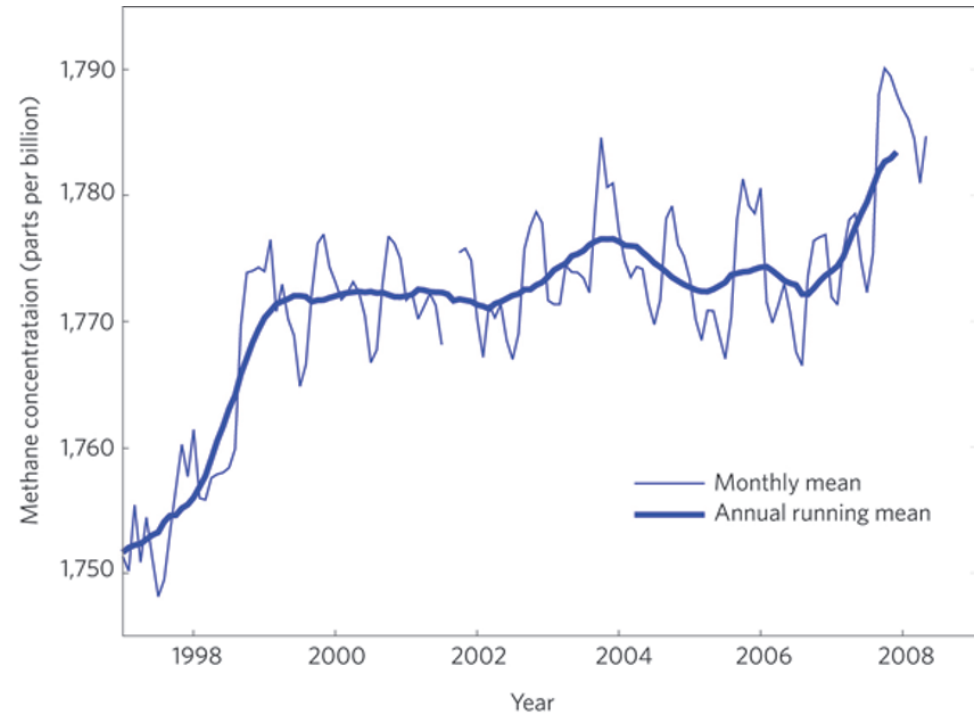

Figure 1 Unexpected rise in global methane levels. The average atmospheric concentration of methane shot up suddenly in 2007, having remained stable for a decade. Data shown are from the Advanced Global Atmospheric Gases Experiment and the Australian Commonwealth Scientific and Industrial Research Organisation, courtesy of Matt Rigby.

ground. "We find that we get a lot more methane seeps where there's permafrost thawing," says Walter.

\section{"These deposits rival fossil} fuels in terms of their size. It's like having a whole additional supply of coal, oil and natural gas out there that we can't control."

\section{James White}

Between 1974 and 2000, methane emissions increased by 58 per cent in the part of northern Siberia where Walter's team have focused their research. In a paper in Nature, they attributed this increase to melting permafrost, which forms ponds and lakes on the land surface ${ }^{1}$. What's more, they found that a positive feedback had kicked in: Pleistocene-age carbon was being released as methane, which was triggering the loss of even more ancient carbon from the permafrost. Walter and her colleagues reckon that ancient carbon stored here would boost current levels of atmospheric methane ten-fold if it were to escape ${ }^{2}$. All in all, Walter and colleagues warn, Siberia's still-frozen, ice age-era carbon could be a 'methane time bomb'. Scientists are hesitant to speculate on whether and when this time bomb will be detonated. But, says Walter, "Yedoma is warming and thawing now. Acceleration should occur during the next century."

\section{SPIKE SOURCE}

A sign that this acceleration may have already begun comes from scientists who closely monitor concentrations of the gas in the atmosphere. Having remained stable for a decade, atmospheric levels of methane suddenly spiked in 2007 (Fig. 1). It's not yet clear where the extra emissions came from and why methane levels increased uniformly across the globe. But there may be an explanation for the rise in emissions in the Northern Hemisphere, at least. Says Matthew Rigby, a postdoctoral researcher at the Massachusetts Institute of Technology in Cambridge and lead author of a recent study ${ }^{3}$ analyzing the trend, "If I had to put my money on it, I'd put it on increased emissions from the northern wetlands." This, however, invites the question, why are northern wetlands releasing more methane? "Some are worried it may be the start of permafrost melting," says Rigby. "We can't rule that out."

Ed Dlugokencky, an atmospheric chemist with the US National Oceanographic and Atmospheric Administration in Boulder, Colorado, who oversees their atmospheric-methane measurement program, says indications are that global methane levels remained high in 2008, but he expects to see a return to previous levels over the long 


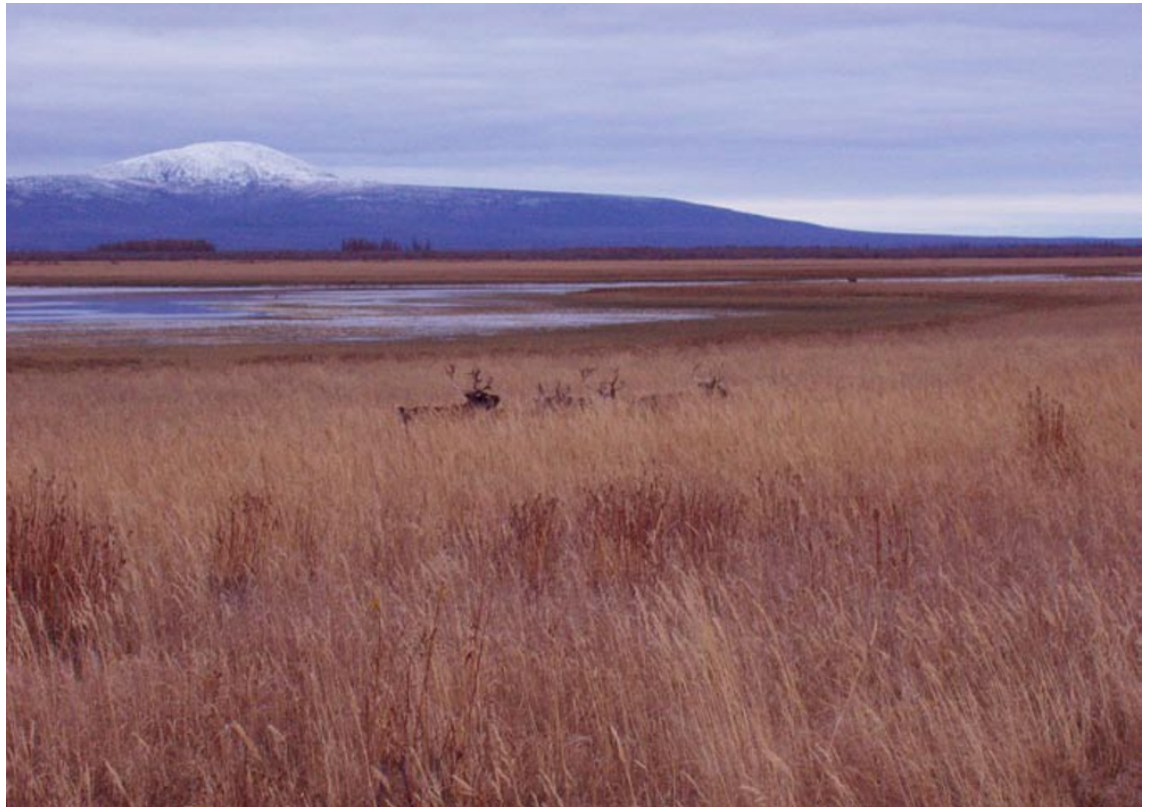

Pleistocene Park in northeast Siberia, where scientists are reintroducing animals in an attempt to restore the ancient steppe-grassland ecosystem and limit methane emissions from warming permafrost.

term. "If I had to make a prediction about what's going to happen in the future based on the last three decades of observations, I would say that there's a reasonable chance methane will continue to stay flat or even decrease before we see the effects of a warming climate on methane sources," says Dlugokencky. White agrees and says it's too early to tell whether this is a blip on the radar or a true signal that change is afoot. "I think we're going to need to see two to three years or more with increased methane in order to make a strong statement that we're beginning to see permafrost degradation resulting in methane increase," says White.

But what's evident is that if methane emissions start to escape en masse, shallow reserves under the Arctic tundra - and those along continental shelf margins - will probably be the first to give. A temperature rise of as little as $1{ }^{\circ} \mathrm{C}$ at the sea floor could dissolve shallow subsea clathrates, for example, according to a recent study by Matthew Reagan and George Moridis of the Lawrence Berkeley National Laboratory in Berkeley, California ${ }^{4}$. Deep ocean hydrates, on the other hand, are more likely to stay intact as temperatures rise, at least for moderate amounts of warming. David Archer, an oceanographer from the University of Chicago, and his colleagues found that if temperatures in the deep ocean were to rise by about $3{ }^{\circ} \mathrm{C}$, nearly a trillion tonnes of carbon could be released from subsea clathrates ${ }^{5}$. Archer points out that the temperature changes at those ocean depths are small so far, but says that "the reason it seems scary is that there's so much methane."

"Between now and 2100, I would worry more about shallow waters and permafrost melt as sources of methane than deep water," says Jean-François Lamarque of the US National Center for Atmospheric Research in Boulder. In a recent study ${ }^{6}$, Lamarque looked at how doubling atmospheric $\mathrm{CO}_{2}$ concentrations might affect subsea hydrates. He concluded that warming of the ocean floor during the coming century is unlikely to induce a methane-clathrate release in the deep ocean of "atmospheric significance".

Research by Duane Froese of the University of Alberta and colleagues suggests that this may also be true of methane buried deep on land. They discovered permafrost several metres below the surface in northwestern Canada that dated back more than 700,000 years, suggesting that it has survived climates warmer than today's ${ }^{7}$. Froese says that while their findings suggest deep permafrost is stable, the research has no bearing on shallower sites. "There is a real need for concern about future warming and shallow permafrost instability," says Froese.

If such concerns are borne out, the change wouldn't be unprecedented. During the Pleistocene, which lasted from about 1.8 million years ago until 10,000 years ago, ice sheets cloaked much of North America and Eurasia, and animals such as woolly mammoths and mastodons lumbered around on the frozen, icy tundra. This era was brought to an abrupt end by a rapid warming spell that caused widespread glacial melting, raising sea levels by more than a hundred metres and triggering mass extinctions. According to research by Katey Walter and her colleagues, methane bubbling up from the bottoms of Arctic lakes accounted for between 30 and 87 per cent of the rise in atmospheric methane that helped bring an end to the Pleistocene ${ }^{8}$. These lakes now account for six per cent of global methane emissions. "So we know that they have the potential to become an even bigger source in the future," says Walter.

More recently, Martin Kennedy and colleagues reported in Nature that a massive release of methane some 635 million years ago might have spelled the end of the last 'snowball Earth' period, when ice sheets stretched as far as the Equator ${ }^{9}$. According to their analysis, this was a period of abrupt glacial melting and destabilization of methane hydrates. Although there is not widespread agreement about what role methane has played in periods of abrupt climate change in Earth's history, "When we look at the geologic record, at critical thresholds, methane is implicated in almost all of those occurrences," says Kennedy.

\section{RESTORE OR RELEASE}

Aside from getting a better handle on how methane might affect our future, scientists are also considering how we could prevent its release. One innovative approach is a scientific reserve in northeast Siberia known as Pleistocene Park, created by Sergey Zimov, director of the Northeast Science Station in Cherskii, Russia. In a bid to keep the permafrost frozen, Zimov is working to reintroduce animals that resemble Pleistocene megafauna and to restore the ancient steppe-grassland ecosystem. Steppe vegetation reflects more sunlight than the now-dominant forests and wetlands, reducing summer heat. In addition, animals trample down the snow when they forage, and the resulting denser snowpack provides greater insulation, allowing the ground below it to freeze much deeper in the wintertime, explains Zimov. "All we need to do to turn the current low-productivity ecosystems into high-productivity steppe is to bring in high enough densities of animals and then let them transform the ecosystem themselves," he says. The north Siberian plains contain some 500 billion tonnes of carbon stored as permafrost, so if 
they were to melt, says Zimov, "all this carbon would quickly be transformed to greenhouse gases." So far, Zimov and his colleagues have introduced horses, reindeer and moose, and they are hoping to bring in musk oxen, mountain goats and bison in the near future.

In a few other places in the world, including the Netherlands, methane gas escaping naturally from seeps is being captured and used as an energy source. Walter says that there is potential to apply this on a local scale in places such as Alaskan villages, thereby harnessing the natural gas and reducing the need to ship diesel fuels to remote locations.

But while such efforts at reining in methane march forward, energy prospectors are exploring how they might be able to tap vast stores of the gas on the sea floor - a practice that could potentially introduce sequestered gases into the environment. Rather than harnessing gases that are already escaping, this would involve mining gas hydrate reservoirs for energy. One such project between the US government and energy giant BP has begun modelling gas hydrates to determine whether the process is commercially viable. Other countries, including Japan, South Korea, China and India, are investing substantial amounts into similar research. The United States is believed to hold some 5,700 trillion cubic metres of gas hydrates - that's nearly 9,000 times the country's current annual natural gas consumption, making the resources potentially highly lucrative. But for their part, some climate researchers hope that methane clathrates will stay right where they are for a very long time. "It sounds to me technologically very difficult if not dangerous," says White.

"This is a sleeping giant that should be left asleep."

For now, scientists are working quickly to answer pressing, yet basic questions, such as how much methane could be released as a result of warming, and when. "We first need sound science to use as a basis for understanding what the methane emissions are and how they may be changing right now," says Ruppel. In the meantime, how concerned should we be about the possibility of climate catastrophe resulting from methane? "It's probably safe to say that we don't know," says White. "But if there's a ticking bomb in the room, you'd like to know the possibility of it going off. The fact that it's there at all is unnerving."

\section{Published online: 5 March 2009}

\section{doi:10.1038/climate.2009.24}

\section{References}

1. Walter, K. M. et al. Nature 443, 71-75 (2006).

2. Walter, K. M., Smith, L. C. \& Stuart Chapin III, F. Phil. Trans. R. Soc. A 365, 1657-1676 (2007)

3. Rigby, M. et al. Geophys. Res. Lett. doi: 10.1029/2008GL036037 (2008)

4. Reagan, M. T. \& Moridis, G. J. J. Geophys. Res. 113, C12023, doi:10.1029/2008JC004938 (2008).

5. Archer, A., Buffett, B. \& Brovkin, V. Proc. Nat. Acad. Sci. USA doi/10.1073/pnas.0800885105 (2008).

6. Lamarque, J. Geophys. Res. Lett. 35, L19806 (2008).

7. Froese, D. G., Westgate, J. A., Reyes, A. V., Enkin, R. J. \& Preece, S. J. Science 321, 1648 (2008).

8. Walter, K. M. et al. Science 318, 633-636 (2007).

9. Kennedy, M., Mrofka, D. \& von der Borch, C. Nature 453, 642-645 (2008).

Amanda Leigh Mascarelli is a freelance science writer based in Denver, Colorado.

\section{naturechINA然}

Your one-stop web portal, highlighting significant research from scientists in mainland China and Hong Kong. Visit www.nature.com/nchina

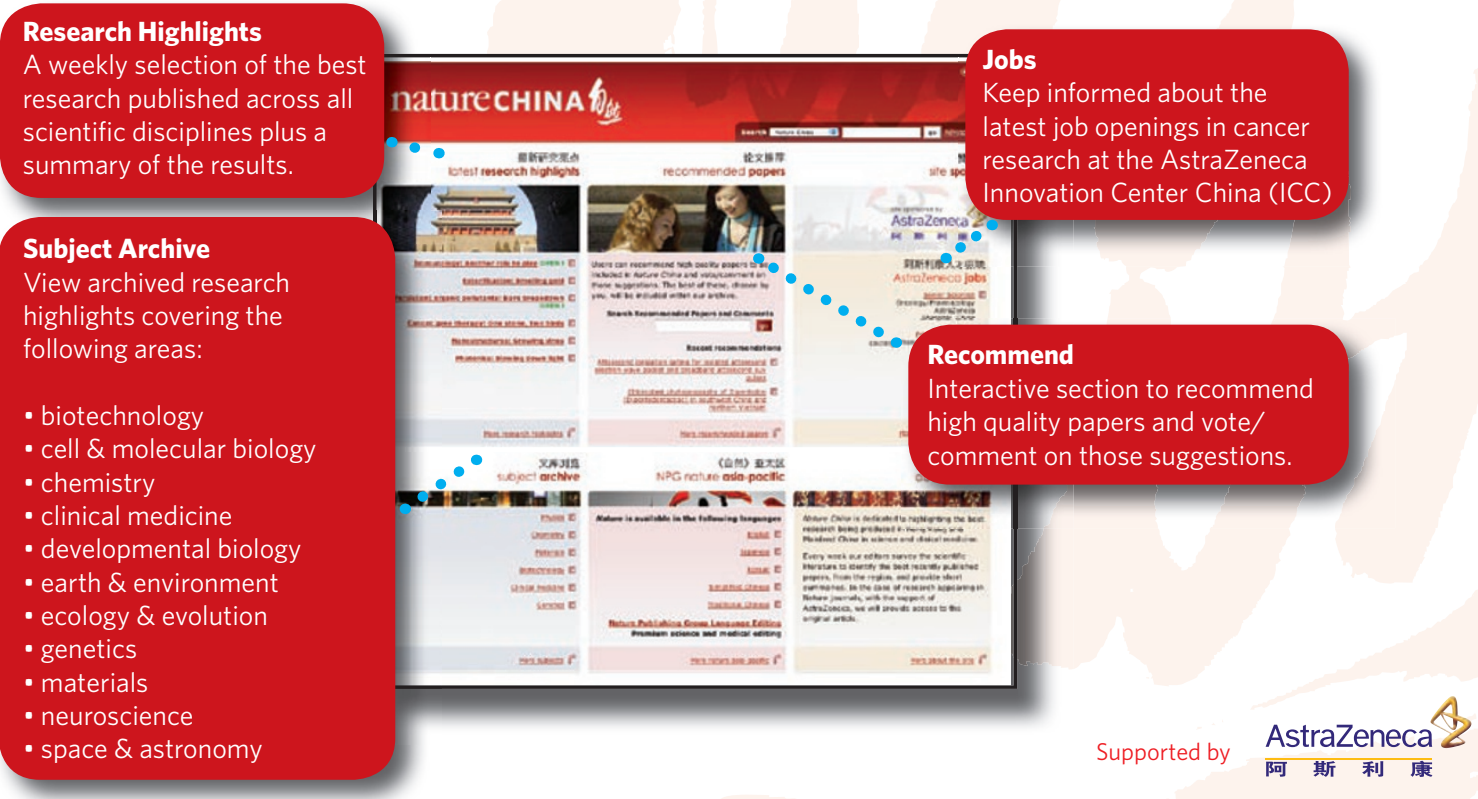

